\title{
Role of Community Health Practitioners in National Development: The Nigeria Situation
}

\author{
Asiton-a Solomon Ibama*, Pauline Dennis \\ Community Health Services Department, Rivers State Primary Health Care Management Board, Port Harcourt, \\ Nigeria \\ Email: *nachpn2015@gmail.com
}

Received 6 June 2016; accepted 22 July 2016; published 25 July 2016

Copyright (C) 2016 by authors and Scientific Research Publishing Inc.

This work is licensed under the Creative Commons Attribution International License (CC BY). http://creativecommons.org/licenses/by/4.0/

c) (i) Open Access

\section{Abstract}

This is a review paper that brings to focus, concepts of Community Health Practice that connect Community Health Practitioners' Roles to National development in view of its composite index improvement measure of social welfare services provision among others for the citizens of a country over time, with particular emphasis on medical care component of such index aimed at reduction in diseases and poverty in the population. The objective of the review work is to determine the extent to which Community Health Practice, particularly by Community Health Practitioners is capable of ensuring National Development in democratic governance or otherwise, in the context of our country, Nigeria. The methodology applied was traditional review of published literatures concerning the subject and findings of operational research of programme implemented by Community Health Practitioners at the Primary Health Care facilities and household level in the communities. This paper emphasizes on Primary Health Care services delivery contribution to National Development, since it is the level where Community Health Practitioners are mainly commissioned to render their services. Home-Based Care Strategy for Integrated Maternal, Newborn and Child Health piloted in three (3) local government areas (Ahoada West, Etche and Oyigbo) in Rivers State, Nigeria, in 2012 and implemented by Community Health Practitioners, aimed at reducing maternal, newborn and child morbidity and mortality by $20 \%$ by 2015 in line with the United Nations (UN) Millennium Development Goals 4 and 5, had been shown to achieve an average of $26 \%$ improvement in utilization of maternal and newborn health services, an average of $27 \%$ overall reduction in maternal malnutrition status, an average of $14 \%$ overall improvement in under 5 years malnutrition status among others in 2013 on comparing with baseline indicators. Nigeria also attained $\mathbf{8 0 \%}$ coverage in routine immunization in most vaccine preventable diseases except Tetanus Toxiod (TT) 2 (54\%) in 2013 to achieve herd immunity of the community to prevent transmission of disease pathogen to cause a disease. Community Health Practitioners are the frontline Primary Health Care Professionals charged with the responsibility of implementation of immunization programmes in Nigeria and therefore contributing significantly to

${ }^{*}$ Corresponding author. 
the prevention and control of targeted vaccine preventable diseases in Nigeria Health System. Our findings on factors militating against Community Health Practitioners' Roles in National Development as elicited in this paper may form basis for empirical studies to determine the level of significance of each of these factors. In conclusion, it is when the Community Health parameters are adequately addressed that we can ensure sustainable National Development and we can say we have succeeded in our various strategic agenda of government at whatever level that makes up the complex whole. This brings to fore, the importance of the roles of Community Health Practitioners in health care delivery to National Development in the context of our country, Nigeria.

\title{
Keywords
}

\author{
National, Development, National Development, Community, Community Health Practitioners, \\ Roles, Primary Health Care, Promotive, Preventive, Curative, Rehabilitative, Accessibility, \\ Acceptability, Affordability, Rural, Nigeria Health System
}

\section{Introduction}

Community Health and National Development are inextricably tied together, in which the evaluation of National Development cannot be complete without the Community Health component. This review paper seeks to look at the extent to which Community Health Practice, particularly by Community Health Practitioners is capable of ensuring National Development in democratic governance or otherwise, in the context of our country, Nigeria. For us to do this to the reasonable understanding of what the subject entails, we shall look at the separate key words or concepts implied, then we bring to focus specific roles of Community Health Practitioners in National Development, factors militating against such roles and to draw conclusion in these perspectives.

\subsection{What is National Development?}

The term National Development is framed from two entities-National and Development. The Longman dictionary of contemporary English, viewed National as a phenomenon embracing a whole nation. On the other hand, Development as a concept is difficult to have a universally accepted definition. According to [1], development is taken to involve not only economic growth, but also notion of equitable distribution, provision of health care, education, housing and other essential services all intended to improve the individual and collective quality of life. While in the view of [2], development is an idea that seeks in all ramifications to improve the conditions of human existence. Furthermore, it implies improvement in material well being of all citizens, not the most powerful and rich alone, in a sustainable way such that today's consumption does not imperil the future, it also demands that poverty and inequality of access to the good things of life be removed or drastically reduced. It seeks to improve personal physical security and livelihoods and expansion of life chances.

It is therefore, unequivocally clears that development as a concept is not just an economic exercise alone, but reaches out to involve both socio-economic and political issues and transcends all aspects of societal life.

National development therefore can be described as the overall development or collective socio-economic, political as well as religious advancement of a country or nation. This is best achieved through development planning, which can be described as the country's collection of strategies mapped out by the government [3].

National development is also seen as the ability of a country or countries to improve the social welfare of the people for example by providing social amenities like quality education, potable water, transportation infrastructure, medical care, etc., with the aim of achieving increase in real per capita income as well as reduction in inequality, poverty, illiteracy and diseases. However, our emphasis in this paper is health care delivery aspect, more so the primary health care component within the frame works of its contribution to national development.

\subsection{What Is Health?}

Health they say is Wealth and wealth is created and/or measured by factors of productivity. Productivity; in the present context means a measure of the health care needs of the public so provided in comparison to resources 
put in place to do so.

Effective service delivery in the health sector entails several factors and/or components that must be harnessed adequately in a synergistic manner to achieve the aims and aspiration of health care as encapsulated in its variable terms of Promotive, Preventive, Curative and Rehabilitative health care services.

The World Health Organization (WHO) defines health in the year 1948 as a "complete state of physical, mental and social well-being and not merely the absence of disease or infirmity". Whilst criticized as too utopian and unachievable by some, [4] [5], it aptly presents the broad nature of health in its many meanings, influences, and outcomes, guiding its conception away from the purely biomedical perspective. This clearly shows the complexity involved in the provision of health care needs of the public and hence its measurement in terms of productivity as earlier defined which are bound to vary depending on the aspect that is being viewed and the associated pattern of interpretation at the circumstance, because health is dynamic in nature. It is probably in realization of this, that the Executive Board of the World Health Organization (WHO) considered redefining "health" by inclusion of the fourth dimension of health (spiritual health) as thus: "A dynamic state of complete physical, mental, social and spiritual well being, and not merely the absence of disease or infirmity" [6].

\subsection{What are Community and Community Health?}

Community is the hub of Community Health Practice, anything short of that is not considered as Community Health Practice. It is the essential laboratory for practice of teaching, training and research in the subject of community medicine/health [7].

The definition of community has been varied because of its diversity and complexity, such that no common or universally acceptable definition is attempted. Community is also seen as a group of people living within a common geographical boundary that may not necessarily be of the same origin as in language, culture and practices, but are often of the spirit of joint ownership of issues of common interest and advancement. According to [8], a community is a whole entity that functions because of the interdependence of its parts or subsystems. Eight subsystems plus the community core are identified. The community core is; history, socio-demographic characteristics, vital statistics, values/beliefs/religions, while the eight subsystems are; Physical environment, Education, Safety and transportation, Politics and government, Health and social services, Communication, Economics and recreation.

The idea of the community as the centre of health services delivery was advocated as far back in 1960s. From the concept of Basic Health Services, Primary Health Care emerged. In this regard, the principle of health services in relation to availability, accessibility, acceptability and appropriateness became important considerations in WHO health policy from the late 1960s and into the 1970s [9].

In the works of [10], Community Health is defined in the following perspective:

1) Part of medicine which is concerned with the health of the whole population and the prevention of diseases from which the population suffers.

2) It identifies the root causes of diseases and health problems not only from the individual but also from family, the community and the environment.

3) The community resources are utilized principally in solving their problems. The resources from government and private sector can also be used.

4) It aims at giving the highest level of health for all people in the community and such level includes that of physical, mental, moral, social and spiritual health.

In the reasoning of [11], Community Health consists of principles and practices aimed at achieving prevention of premature death, disabilities and diseases through organized Community efforts with a view to assuring the promotion of optimal health of members of a Community in the context of their environment. Optimal health is said to mean a balance of physical, emotional, social, spiritual and intellectual health.

Community Health could also be seen as the application of simple but scientifically sound and culturally acceptable methods and skills in the prevention, promotion, rehabilitation and or treatment of health conditions in the population or community in reference.

"Community Health" parameters are different from health parameters of an individual. Community health can be measured through indicators of economics such as Gross National Product, Gross National Income and Per Capita Income, as well as life expectancy, under five mortality, infant mortality, literacy level, composite index like human development index, and maternal mortality rate [12]-[14]. The other indicators of community health are environmental indicators, demographic, health services, health care utilization and health policy indicators [7]. 
A community is seen to be healthy if it enjoys sound health where disease and death rate are considerably low, it is not threatened with bad environments and its economy is sound and the health practices are sound and based on scientific evidences. It is also, seen to be healthy if it records high literacy level and having a balanced demographic sex ratio and the people live long, quality of life is good and human development index is high.

A village is equally seen to be healthy when it has; safe source of improved water supply, safe method of waste water disposal, paved streets, disposal of garbage, refuse and animal excreta by manure pits, people use sanitary latrines, female literacy is high, girls enrolment is universal, deliveries are conducted by trained persons, birth rate and death rate are within acceptable limits, immunization coverage is high and housing condition is $\operatorname{good}[7]$.

\subsection{Who Are Community Health Practitioners?}

Community Health Practitioners are Primary Health Care Professionals who had undertaken a standard training programme and passed the examinations set by the training institution and national regulatory body meant for the cadre and licensed [15]. They were created in 1978 by the then Military administration to work at the Primary Health Care system, with the aim of correcting the short-fall observed during third National Development Plan (1975-1980) period of our country, Nigeria. According to [16], Community Health Practitioners are "core" polyvalent workers and these have remained the core Primary Health Care Workers in Nigerian Primary Health Care system. It is a family comprising:

Primary Health Care Tutors,

Community Health Officers,

Community Health Supervisors which training was stopped in 1990,

Community Health Assistants (now Community Health Extension Workers (CHEWs), and

Community Health Aides (now Junior Community Health Extension Workers (JCHEWs).

The CHEWs and JCHEWs, the most important members of the Primary Health Care, are intended to be based in the community ( $50 \%$ and $80 \%$ of the time respectively), particularly, in the villages where they will motivate the community members to action in the provision of health services. In this regards, they are seen as architects of Community participation-a prerequisite for transforming a community from its traditional past to the age of science.

\subsection{What Is Primary Health Care?}

The concept of Primary Health Care started when the World Health Assembly at a meeting of health professionals from all over the world at Alma-Ata in U.S.S.R in September, 1978, wherein they propounded a new concept of health care delivery-Primary Health Care. Nigeria launched a national health policy in October 1988, the bedrock of the policy was primary health care which form the integral part of the national health care system.

The conference defined Primary Health Care as essential health care based on practical, scientifically sound and socially acceptable methods and technology, made universally accessible to individuals and families in the community through their full participation at a cost the community and country can afford to maintain at every stage of their development in the spirit of self reliance and self determination.

As an integral part of the country's health system, it remained the central function and main focus, and of the overall social and economic development of the community. It is the first level of contact of individuals, the family and community with the national health system bringing health care as close as possible to where people live and work and constitutes the first element of continuing health care process.

The concept of Primary Health Care is therefore explained in the following perspective:

1) It integrates preventive, promotive and curative services using the type of technology the community will accept at the level it can afford with an efficient and effective system of supervision and referral.

2) It involves in addition all health sections, all health related sectors. Any aspect of National and Community development in particular, the agriculture, animal husbandry, food and industry, Education, Housing, Public utility and works, Communications and other sectors and demand the coordinated efforts of all these sectors.

3) It also involves a close partnership between the community and government in the development of resources and health care.

The import of the primary health care system is that:

1) Health care should trickle down to the grass-root. This means that there should be better coverage of the 
population with health care services.

2) There should be more emphasis on preventive as well as basic curative services to the majority of the population.

3) Appropriate technology is being used thereby reducing cost and therefore making health care affordable.

4) Appropriate and essential health care is being provided since community diagnosis as a major component of the primary health care is carried out in the local government areas and communities to ensure solving specific prevalent health problems in the context of such communities.

5) The primary health care system is being co-managed by various health development committees which are made up mainly of the local population, therefore, encouraging community participation which pave way for self-reliance and self-determination.

6) Emphasis is laid on inter-sectoral collaboration, therefore, avoiding duplication of efforts that enabled fund to be reserved.

\section{Community Health Practitioners' Roles in National Development}

Report showed that healthcare costs continue to rise as medical care becomes more complex and the burden of disease shifts toward chronic illnesses [17]. Focus on racial and ethnic disparities in health outcomes had also motivated novel methods of serving disadvantaged populations [18].

Community health through the application of primary health care principles and concepts focuses more on the well-being of an entire population rather than that of the individual. Investment in human health had been a powerful means to encourage economic growth, protect the environment, and reduce poverty [19]. Most public health investment-for instance, immunization or safe water-bring with them benefits larger than their costs.

Community Health Practitioners, particularly, the CHEWs and JCHEWs having constant touch with the households in their community-based duties and "while diagnosing and treating common conditions with simple but scientifically sound measures, identifying pregnant women and ensuring that they deliver safely, or identifying malnourished children and providing health education in the community, the Community Health Extension Workers mobilizes the community for preventive action as in the building of latrines, wells and roads. This is no mean task and to call them "aides" is therefore misleading and belittles their important role" [20].

Community health practitioners essentially try to prevent problems from happening or re-occurring through implementation of educational programs, administration of health care services, and conduct of research, in contrast to clinical professionals, such as doctors and nurses, who focus primarily on treating individuals after they become sick or injured. They are also concerned with limiting health disparities and a large part of Community health practice by Community Health Practitioners is the fight for health care equity, quality, and accessibility through taking health care services to the door steps of the citizenry in the rural area in particular.

Poor geographical and economic access to health care services had been a bane to effective disease control efforts in Nigeria.

According to [21] official documents, as graphically presented in Figure 1, only an estimated 54\% of Nigerians have access to modern health services. The document also recognizes that "rural communities and the urban poor were not well served". The issue in question is access to available care, what happens to the $46 \%$ of the population without access to modern health, probably medical care [22].

In this regards Community Health Practitioners can contribute significantly to improvements in community members' access to, adherence to and continuity of care, as well as reducing health care costs. This is so because, Community health practice emphasizes coordinated primary and preventive services that promote reductions in health disparities for low-income individuals, racial and ethnic minorities, rural communities, and other underserved populations.

Community health practice also emphasizes reduction in costs to health systems; in this regards, the community health practitioner model of care ensures reduction in the use of costlier providers of care, such as emergency departments and hospitals. What more can we say, the outcome of these services or duties by Community Health Practitioners form the essential ingredient of National Development where ever primary health care is sincerely practiced.

For instance, Home-Based Care Strategy for Integrated Maternal, Newborn and Child Health piloted in three (3) local government areas (Ahoada West, Etche and Oyigbo) in Rivers State, Nigeria, in 2012, targeting about 189,913 population and implemented by Community Health Practitioners, aimed at reducing maternal, newborn 


\section{Accessibility to Modern Health Services in \\ Nigeria \\ - Access to Modern Health Services \\ - Unaccessible to Modern Health Services}

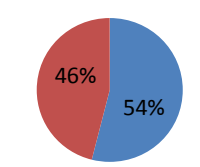

Figure 1. Accessibility to modern health services in Nigeria. Source: [21].

and child morbidity and mortality by $20 \%$ by 2015 in line with the United Nations (UN) Millennium Development Goals 4 and 5, had been shown to achieve an average of $26 \%$ improvement in utilization of maternal and newborn health services, an average of $27 \%$ overall reduction in maternal malnutrition status, an average of $14 \%$ overall improvement in under 5 years malnutrition status among others in 2013 on comparing with baseline indicators, etc. [23]. These variables had been shown from statistics as conditions that contribute to the maternal, newborn and child morbidity and mortality in sub-Saharan Africa, where Nigeria is located.

It is also worthy of note that Nigeria attained $80 \%$ coverage in routine immunization in most vaccine preventable diseases except Tetanus Toxiod (TT) 2 (54\%) in 2013 to achieve herd immunity of the community [24]. Herd immunity is the total immunity level of a community capable of preventing transmission of disease pathogen to cause a disease. It is equally on record that Community Health Practitioners are the frontline Primary Health Care Professionals charged with the responsibility of implementation of immunization programmes in Nigeria and therefore contributing significantly to the prevention and control of targeted vaccine preventable diseases in Nigeria Health System.

In the overall analysis, when a community remains relatively healthy through simple but scientifically sound and culturally accepted methods which are basically from within the community, it is bound to be sustainable and it is only a sustainably healthy community that can venture in other development activities. It is for this reason, quality and affordable health care services is viewed as the foundation of National Development if it were not so "Health" cannot be "Wealth" again. It is a healthy mind in healthy body that brings in several other components to complex whole and in the present context the contribution of Community Health Practitioners by virtue of their roles in health care services delivery to ensure equitable, quality, accessible and affordable primary health care services toward National Development.

\section{Factors Militating against Community Health Practitioners' Roles in National Development}

1) It is true that Primary Health Centres were established in both rural and urban areas in Nigeria with the aim to ensuring equity and easy access to health care; however, the rural populations in Nigeria are seriously underserved when compared with their urban counterparts. What we mean is that, the distribution of Primary Health Care (PHC) facilities is skewed in favour of urban areas, whereas the populations of the rural communities where Community Health Practitioners are commissioned to serve constitute about $70 \%$ of the general population, therefore making coverage a challenge and perhaps the attainment of sustainable National Development in view of our presentation difficult.

2) Most PHC facilities, for Community Health Practitioners to perform their roles are in various stages of disrepair, with equipment and infrastructure being either absent or obsolete, the referral system almost nonexistent, non-functional or facing serious criticism and rejection by the higher level care providers. These had the capacity to affect their morale and motivational spirit as well as to endanger continuity of care, which outcome had never been different from poor utilization of available health care services occasioned by dissatisfaction of services by clients/patients. In such situation, sustainable National Development through Primary Health Care services delivery may be far from expectation.

3) Poor political will by successive governments in funding community health programmes, leading to donor driven health programmes in Nigeria: This also had the capacity to affect sustainability of progress and or 
successes recorded over time, once donors' contributions are withdrawn and so may reduce the efforts put in by Community Health Practitioners in Primary Health Care services delivery to attain National Development.

4) Inadequate number of Community Health Practitioners in the public service as well as their uneven distribution: This equally had the capacity to exert excessive pressure on available manpower, so much so that health care services may be limited to populations that had the advantage to access such services and such had been a challenge to adequate coverage of targeted population to translate to what we can say sustainable National Development, through Primary Health Care services.

5) Poor logistic system in reaching out to difficult-to-reach communities/settlements: Since it is practically impossible to provide functional health facilities in all communities/settlements by government, it behoves that functional logistic system be put in place to carry out planned outreach health care delivery services to make health care services more accessible, to come in line with the concept of National Development. However, this had not been done smoothly, thereby limiting a major role of the Community Health Practitioners and so considered counterproductive to National Development.

6) Lack of understanding of Primary Health Care among health professionals and decision-makers resulting in poor quality services: Primary Health Care is the first level of contact with the National Health System, for preventive and promotive health care services as well as early detection and prompt treatment of cases and referral of more serious cases to the secondary and tertiary levels health care. Rather, what had been observed is that, these preventive and promotive health care services such as immunization and primary infant welfare clinic just to mention but few are carried out even at tertiary level health care (Teaching Hospitals), whose management are necessarily part of the decision making body in Nigeria Health System. This in our consideration exerts negative influence on the decisions of policy makers in making the working environment for Community Health Practitioners conducive and devoid of professional wrangling and role conflict. Obviously, the resultant of this is poor quality health care services that negate sustainable National Development.

7) Inadequate training and retraining programme for Community Health Practitioners commensurate with their responsibilities and roles: One of the cardinal strengths in health care delivery at whatever level is training and retraining, but it had been difficult for Community Health Practitioners to secure approval and sponsorship for in-service training and professional continuing education for proficiency and enhancement of their performance. This in no doubt had been a source of discouragement to Community Health Practitioners to render their all important roles in the health care industry towards National Development.

8) Poor remuneration to Community Health Practitioners that dampens their zeal to render their all important roles towards National Development: The joy of every worker is adequate and regular remuneration in its diverse forms. This had not been easy to come by, as salary, even as not being adequate, had not been so regular; promotion had also not been regular, adequate funding for running health facilities' operations and programme had been no go area. Such situations are inimical to quality health care delivery to attain National Development in the context of this paper.

These factors, as elicited above were findings from interactive sessions of review meetings of Home-Based Care for Integrated Maternal, Newborn and Child Health programme, piloted in three (3) Local Government Areas, namely Ahoada West, Etche and Oyigbo in Rivers State, Nigeria from 2012 to 2014, implemented by Community Health Practitioners in these Local Government Areas, coordinated and supervised by the corresponding author of this paper among other team of supervisors through the Rivers State Primary Health Care Management Board.

\section{Recommendations}

No doubt, these findings may form the basis for empirical studies to determine the level of significance of each of these factors to guide policy formulation and implementation in Primary Health Care services delivery by Community Health Practitioners and indeed other Primary Health Care professionals to achieve sustainable National Development.

Successive governments should address these factors with appropriate policies, legislations and enforcement to sustain the roles of Community Health Practitioners toward National Development.

\section{Conclusion}

The definition of National Development, as presented in this paper, portrays its composite index requirement 
towards achieving economic, socio-demographic and health outcome of a country, state, local government or community, where in community health parameters are fundamental. It is when the Community health parameters are adequately addressed that we can ensure sustainable National Development and we can say we have succeeded in our various strategic agenda of government at whatever level that makes up the complex whole. This brings to fore, the importance of the roles of Community Health Practitioners in health care delivery to National Development in the context of our country, Nigeria.

\section{References}

[1] Naomi, O. (1995) Towards an Integrated View of Human Rights. Hunger Teach Net, 6, 6-7.

[2] Gboyega, A. (2003) Democracy and Development: The Imperative of Local Governance. An Inaugural Lecture, University of Ibadan, Ibadan, 6-7.

[3] Lawal, T. and Oluwatoyin, A. (2011) National Development in Nigeria: Issues, Challenges and Prospects. Journal of Public Administration and Policy Research, 3, 237-241.

[4] Nutbeam (1986) http://www.forcedmigration.org/guides/

[5] Sax (1990) http://www.forcedmigration.org/guides/fmo030/fmo030-9.htmHfmo030-bibl-58

[6] World Health Organization (WHO) (1998) http://www.who.int/en/

[7] Lal, S., Adarsh and Pankaj (2010) Textbook of Community Medicine: Preventive and Social Medicine. 2nd Edition, CBS Publishers and Distributors PVT. Ltd., New Delhi.

[8] Salama, R. (2014) Community Diagnosis. University of Pittsburgh, Pittsburgh. http://www.pitt.edu/-supper-/32011-33001/32491.ppt

[9] Walt, G. (1982) Primary Health Care Approach: How Did It Evolve? Tropical Doctor, 12, 145-147.

[10] Alakija, W. (2000) Essentials of Community Health, Primary Health Care \& Health Management. Medisuccess Publication, Benin.

[11] Abanobi, O.C. (1999) Core Concepts in Epidemiology and Community Health Practice. Opinion Research \& Communications Inc., Owerri.

[12] UNICEF (1998) Rights and Opportunities. The Situation of Children and Women in India, 1998. New Delhi.

[13] UNDP (2004) Human Development Report 2003. New York.

[14] Hindustan Times (2005) New Delhi, 2005 February, 24.

[15] Ibama, A.S. and Dotimi, D.A. (2014) Cultural Practices and the Health of 0-15 years Children in Nigeria: The Role of Community Health Practitioners. International Journal of Development Research, 4, 1281-1284.

[16] Health Reform Foundation of Nigeria (2008) Nigerian Health Review 2007: Primary Health Care in Nigeria: 30 years after Alma Ata. Memm-nat Educational Window Consultant Ltd., Nigeria.

[17] Schroeder, S. (2007) We Can Do Better: Improving the Health of the American People. The New England Journal of Medicine, 357, 1221-1228. http://dx.doi.org/10.1056/NEJMsa073350

[18] Smedley, B., Stith, A. and Nelson, A., Eds. (2003) Unequal Treatment: Confronting Racial and Ethnic Disparities in Healthcare. IOM; The National Academies Press, Washington DC.

[19] World Health Organization (WHO) (2001) Macroeconomics and Health: Investing in Health for Economic Development. http://whqlibdoc.who.int/publications/2001/924154550x.pdf

[20] Ransome-kuti, O., Sorungbe, A.O., Oyegbite, K.S. and Bamisaiye, A. (1999) Strengthening Primary Health Care at Local Government Level, The Nigerian Experience. Academy Press Ltd., Lagos.

[21] Federal Ministry of Health (2006) National Health Policy. In: Nnebe, H., Ed., Policies of the Federal Republic of Nigeria (1999-2007), Quarterly Newsletter of the Health Reform Foundation of Nigeria, Abuja, Vol. 1, Number 1 (New Series), March-April 2012, p. 18.

[22] Ibama, A.S. (2015) Strategies in Disease Control: The Role of Public Health Practitioners. Being a Seminar Paper Presented in Partial Fulfillment of The Ph.D. in Public Health Degree, Federal University of Technology, Owerri.

[23] Ibama, A.S., Dotimi, D.A. and Obele, R. (2015) Community Health Practice in Nigeria—Prospects and Challenges. International Journal of Current Research, 7, 11989-11992. http://www.journalcra.com

[24] NPHCDA (2013) Immunization Coverage in Nigeria. Presentation at National Scientific Conference being hosted by National Association of Community Health Practitioners of Nigeria, 2013. 


\section{Submit or recommend next manuscript to SCIRP and we will provide best service for you:}

Accepting pre-submission inquiries through Email, Facebook, LinkedIn, Twitter, etc.

A wide selection of journals (inclusive of 9 subjects, more than 200 journals)

Providing 24-hour high-quality service

User-friendly online submission system

Fair and swift peer-review system

Efficient typesetting and proofreading procedure

Display of the result of downloads and visits, as well as the number of cited articles

Maximum dissemination of your research work

Submit your manuscript at: http://papersubmission.scirp.org/ 